\title{
Problem drinking and associated factors in older adults in South Africa
}

\author{
K Peltzer ${ }^{1,2}$, N Phaswana-Mafuya ${ }^{1,3}$ \\ ${ }^{1}$ HIV/AIDS/SIT/and TB (HAST), Human Sciences Research Council, Pretoria South Africa \\ 2Department of Psychology, University of Limpopo, Turfloop, South Africa \\ ${ }^{3}$ Office of the Vice Chancellor, Nelson Mandela Metropolitan University, Port Elizabeth, South Africa
}

\begin{abstract}
Objective: Alcohol abuse poses special risks for increased morbidity and mortality among older adults. Little attention has focused on assessing alcohol use and associated factors among older adults in transitional societies such as South Africa. This study aimed to determine the prevalence of alcohol use and associated factors in older South Africans who participated in the Study of Global Ageing and Adults Health (SAGE) in 2008. Method: We conducted a national population-based cross-sectional study with a sample of 3840 aged 50 years or older in South Africa in 2008. In this study we analysed data from all 2144 participants who were over 60 years old. The questionnaire included socio-demographic characteristics, alcohol intake as well as comorbidity. Risky drinking was defined in two ways: heavy drinkers ( $>7$ drinks/week) and binge drinkers ( $>3$ drinks/one occasion/week). Results: Four percent of participants reported heavy drinking and 3.7\% binge drinking. Male gender (Odds Ratio (OR) =3.79, Confidence Interval (CI) $=1.38-10.37)$ and white population group (OR=3.01, CI=1.31-6.89) were associated with risky drinking in multivariate analysis; as well as tobacco use (OR=5.25, CI=2.20-12.52) and not being obese (OR=0.14, CI=0.05-0.35). Hypertension, diabetes and depression were not associated. Conclusion: This study reveals moderate rates of risky drinking among older adults (60 years and more) in South Africa that puts them at risk of morbidity. Alcohol problems among older adults are commonly under-recognized, indicating a need for health care worker intervention.
\end{abstract}

Keywords: Alcohol abuse; Prevalence; Risk factors; Older adults; South Africa

Received: 31-01-2012

Accepted: 28-02-2012

doi: http://dx.doi.org/10.4314/ajpsy.v16i2.13

\section{Introduction}

As the population of older adults continues to grow, there is an increased need to reexamine alcohol use in this population. ${ }^{1}$ Alcohol abuse poses special risks for increased morbidity and mortality among older adults ${ }^{2}$ including increased risks for accidents and injuries, hypertension, cardiac dysrhythmic events, cancers, gastrointestinal problems, liver disease, neurocognitive deficits, bone loss and depression. ${ }^{3-5}$ Many older adults take medications that may interact negatively with alcohol. ${ }^{6}$

Alcohol use data of older adults from high income countries indicates that: in Japan, $47.9 \%$ of men and $10.1 \%$ of women drank alcohol almost daily ${ }^{7}$; in the USA, 9\% of elderly Medicare beneficiaries reported unhealthy drinking, with

Correspondence

Prof K Peltzer

Human Sciences Research Council, Private Bag X41, Pretoria 0001

South Africa

email: KPeltzer@hsrc.ac.za higher prevalence in men (16\%) than women $(4 \%)^{8}$; and also in the USA, Schultz et al. ${ }^{9}$ reported that about $15 \%$ of older persons in a rural state were at risk for alcoholism. Studies from low and middle income countries found that: among older adults in Brazil, 12\% reported heavy drinking behavior, while $10.4 \%$ and $2.9 \%$ were binge drinkers and alcohol dependent respectively ${ }^{10}$; among rural residents 50 years and older in Tanzania, $4.3 \%$ and $6.0 \%$ of men and women respectively, had more than one drink per day ${ }^{11}$; and in a national survey in 2004 in Thailand, 13.0\% of older persons (55 years and above) were hazardous or harmful alcohol drinkers. ${ }^{12}$

Factors associated with alcohol misuse or abuse in older adults have been identified as follows: higher or lower education and income; better health status; male sex; younger age; smoking; being white; being divorced, separated, or single; self-reported depressive symptoms; psychological distress; race and ethnicity; and religious involvement. 8,10,13-17

There are very few studies investigating alcohol use among older adults in low and middle income countries. 
Therefore the aim of this study was to assess the prevalence of alcohol use and associated factors in older South Africans who participated in the Study of Global Ageing and Adults Health (SAGE) in 2008.

\section{Methods}

\section{Sample and procedure}

We conducted a national population-based cross-sectional study with a sample of 3840 aged 50 years or older in South Africa in 2008. In this study we analysed data from all 2144 participants who were over 60 years of age. The SAGE sample design entails a two-stage probability sample that yields national and sub-national estimates to an acceptable precision at provincial level, by locality type (urban and rural), and by population group (including black, coloured, Indian or Asian and white). The overall response rate among those aged 50 years or older was 60\%. The Global Study on Ageing (SAGE) survey was carried out in South Africa in partnership between the World Health Organization (WHO), the National Department of Health, and the Human Sciences Research Council (HSRC).

\section{Ethics}

The study was approved by the Human Sciences Research Council Research Ethics Committee and the National Department of Health.

\section{Measures}

\section{Alcohol use}

Lifetime alcohol use was assessed with the question "Have you ever consumed a drink that contains alcohol (such as beer, wine, spirits, etc.)?" Response options were "Yes" or "No, never". Lifetime alcohol users were asked about current (past month) alcohol use, and current alcohol users were asked "During the past 7 days, how many drinks of any alcoholic beverage did you have each day?" Finally past 12 months alcohol use frequency and average consumption was assessed; First "In the last 12 months, how frequently [on how many days] on average have you had at least one alcoholic drink?" Response options included l=less than once a month to 4 =five or more days a week; Second "In the last 12 months, on the days you drank alcoholic beverages, how many drinks did you have on average?" Response option was the number of drinks.

Risky drinking was defined in two ways: heavy drinkers (>7 drinks/week) and binge drinkers (>3 drinks/one occasion/week). These are considered 'risky drinking' according to the The National Institute on Alcohol Abuse and Alcoholism (NIAAA). ${ }^{18}$ Exceeding these limits is associated with interpersonal and functioning problems for elders ${ }^{19}$, who have higher sensitivity and impaired ability to metabolize alcohol. ${ }^{20}$

\section{Tobacco use}

Lifetime tobacco use was assessed with the question "Have you ever smoked tobacco or used smokeless tobacco?" Lifetime tobacco users were asked "Do you currently use (smoke, sniff or chew) any tobacco products such as cigarettes, cigars, pipes, chewing tobacco or snuff?" The response options were "Yes, daily", "Yes, but not daily" and "No, Not at all."

\section{Anthropometry}

Height, weight, waist and hip circumferences were measured. Body mass index (BMI) was used as an indicator of obesity, and the waist/hip ratio (WHR) was used as an indicator of central obesity.

\section{Physical activity}

Physical activity was measured using the General Physical Activity Questionnaire (GPAQ). The instrument gathers information on physical activity in three domains (activity at work, travel to and from places, and recreational activities), as well as time spent on sitting. The questionnaire also assesses vigorous and moderate activities performed at work and for recreational activities.

Information on the number of days in a week spent on different activities and time spent in a typical day for each activity was also recorded. ${ }^{21}$

\section{Overall self-rated health status}

This was based on respondents' assessment of their current health status on a 5-point scale in response to the question: "In general, how would you rate your health today?" Response categories were: very good, good, moderate, bad and very bad. From this a dichotomous measure was coded 0 if response was 'very good' or 'good' or 'moderate'; and 1 if response was 'bad' or 'very bad'.

\section{Activity limitation}

Difficulty an individual may have in executing tasks or actions was assessed with one item: "Overall in the last 30 days, how much difficulty did you have with work or household activities?" Response options ranged from $\mathrm{l}$ =none to 5 =extreme/cannot do. From this we created a dichotomous measure coded 0 if response was 'none' or 'mild' or 'moderate'; and 1 if response was 'severe' or 'extreme/cannot do.'

Symptom-based depression in the past 12 months was assessed based on the World Mental Health Survey version of the Composite International Diagnostic Interview. ${ }^{22}$ The diagnosis of depression was based on the International Classification of Diseases tenth revision (ICD-10) diagnostic criteria for research, for depressive episodes ${ }^{23}$, and was derived from an algorithm that took into account respondents' reporting symptoms of depression during the past 12 months. ${ }^{24}$

Finally, participants were asked about a list of chronic and other illness conditions they had been diagnosed with including diabetes and hypertension.

\section{Data analysis}

The data were entered using CSPro and analysed using STATA Version 10. Data was weighted using post-stratified individual probability weights based on the selection probability at each stage of selection. Individual weights were post-stratified by province, sex and age-groups according to the 2009 Medium Mid Year population estimates from Statistics South Africa. (Available at: http://www.stats.sa.gov.za/publications/P0302/P03022009.pdf.) Weights were not normalised. Outliers were removed after examining the data using boxplot analyses. For physical activity, in addition to the total minutes of activity, the activity volume was also computed by weighing each type of activity by its energy requirement in metabolic equivalents (METs). One MET was 
defined as the energy cost of sitting quietly, and was equivalent to a caloric consumption of $1 \mathrm{kcal} / \mathrm{kg} /$ hour. A MET-minute showed the total activity volume on a weekly basis, and was calculated by multiplying time spent on each activity during a week, by the MET-values of each level of activity. MET-values for different level activities were set as 4 MET for moderate intensity physical activity, 8 MET for vigorous physical activity, and 4 MET for transport-related walking or cycling. The total physical activity for GPAQ2 was calculated as the sum of total moderate, vigorous, and transport-related activities per week. The number of days and total physical activity MET minutes per week were used to classify respondents into three categories of low, moderate, and high level of physical activities. Less than 600 MET-minutes per week was classified as low physical activity. ${ }^{21}$

Multivariate logistic regression identified sociodemographic and selected chronic conditions (obesity, diabetes and hypertension), depression, tobacco use and health risk (low physical activity) factors as predictors of problem drinking in the data.

\section{Results}

\section{Sample characteristics}

The sample included 2144 participants (1263 women and 881 men), $61.1 \%$ were 60 to 69 years old and $38.9 \% 70$ years or older. The largest population group consisted of Black African (70.7\%), followed by Coloured (13.1\%), Whites (11.6\%) and Indian or Asian (4.5\%). More than half (52.1\%) were currently married or cohabitating, 33\% widowed, 10.2\% never married and $4.7 \%$ separated or divorced. About half (48.8\%) had at least primary school education completed. Almost two-thirds of the sample (63.2\%) resided in urban as opposed to rural areas (36.8\%). In terms of alcohol use, 23.7\% were lifetime and 10.7\% past month or current alcohol users. Four percent of participants reported heavy drinking and 3.7\% binge drinking (see Table I).

\section{Table I: Characteristics of participants aged 60 and over (SAGE, 2008)}

\begin{tabular}{|c|c|c|c|}
\hline Socio-demographic & & $N=2144$ & $\%$ \\
\hline Gender & $\begin{array}{l}\text { Male } \\
\text { Female }\end{array}$ & $\begin{array}{l}881 \\
1263\end{array}$ & $\begin{array}{l}42.2 \\
57.8\end{array}$ \\
\hline Age (years) & $\begin{array}{l}60-69 \\
70 \text { and over }\end{array}$ & $\begin{array}{l}1233 \\
911\end{array}$ & $\begin{array}{l}61.1 \\
38.9\end{array}$ \\
\hline Population group & $\begin{array}{l}\text { African Black } \\
\text { White } \\
\text { Coloured } \\
\text { Indian or Asian }\end{array}$ & $\begin{array}{l}1134 \\
170 \\
375 \\
165\end{array}$ & $\begin{array}{l}70.7 \\
11.6 \\
13.1 \\
4.5\end{array}$ \\
\hline Marital status & $\begin{array}{l}\text { Single } \\
\text { Married } \\
\text { Separated/Divorced } \\
\text { Widow }\end{array}$ & $\begin{array}{l}212 \\
1014 \\
101 \\
779\end{array}$ & $\begin{array}{l}10.2 \\
52.1 \\
4.7 \\
33.0\end{array}$ \\
\hline Education level & $\begin{array}{l}\text { Less than primary } \\
\text { Primary } \\
\text { Secondary } \\
\text { More than secondary }\end{array}$ & $\begin{array}{l}1119 \\
492 \\
415 \\
86\end{array}$ & $\begin{array}{l}51.2 \\
22.5 \\
21.5 \\
4.8\end{array}$ \\
\hline Wealth quintile & $\begin{array}{l}\text { Lowest } \\
\text { Second } \\
\text { Middle } \\
\text { Fourth } \\
\text { Highest }\end{array}$ & $\begin{array}{l}399 \\
402 \\
397 \\
469 \\
462\end{array}$ & $\begin{array}{l}20.0 \\
17.9 \\
17.4 \\
21.8 \\
22.9\end{array}$ \\
\hline Geolocality & $\begin{array}{l}\text { Rural } \\
\text { Urban }\end{array}$ & $\begin{array}{l}749 \\
1392\end{array}$ & $\begin{array}{l}36.8 \\
63.2\end{array}$ \\
\hline Alcohol use & $\begin{array}{l}\text { Ever used alcohol } \\
\text { Alcohol use in past month }\end{array}$ & $\begin{array}{l}548 \\
292\end{array}$ & $\begin{array}{l}23.7 \\
10.7\end{array}$ \\
\hline Risky drinking & $\begin{array}{l}\text { Heavy drinker } \\
\text { Binge drinker }\end{array}$ & $\begin{array}{l}106 \\
97\end{array}$ & $\begin{array}{l}4.0 \\
3.7\end{array}$ \\
\hline Co-morbidity & $\begin{array}{l}\text { Hypertension } \\
\text { Diabetes } \\
\text { Depression } \\
\text { Tobacco use } \\
\text { Obesity }\end{array}$ & $\begin{array}{l}700 \\
237 \\
68 \\
435 \\
839\end{array}$ & $\begin{array}{l}36.7 \\
11.3 \\
3.7 \\
18.6 \\
45.8\end{array}$ \\
\hline
\end{tabular}




\section{Associations between risky drinking, socio-demographics} and co-morbidity

Regarding socio-demographics, only male gender and white population group were associated with risky drinking in multivariate analysis; as well as tobacco use and not being obese. Hypertension, diabetes and depression were not associated (see Table II).

\section{Discussion}

The study found a moderate rate of risky drinking among persons 60 years and older in South Africa. Other studies from low and middle income countries seemed to have identified high alcohol problem drinking among older adults. ${ }^{10-12}$ Public health interventions should be targeted at alcohol problem drinking in older adults.

\section{Table II: Associations between risky drinking, socio-demographics and co-morbidity}

\begin{tabular}{|c|c|c|c|c|}
\hline & Heavy drinker & & Binge drinker & \\
\hline & UOR (95\% Cl) & $A O R(\% \% C l)$ & UOR (95\% Cl) & AOR (\% \% Cl) \\
\hline $\begin{array}{l}\text { Gender } \\
\text { Female } \\
\text { Male }\end{array}$ & $\begin{array}{l}1.00 \\
3.80(1.64-8.83)^{\star \star}\end{array}$ & $\begin{array}{l}1.00 \\
3.55(1.05-12.02)^{\star}\end{array}$ & $\begin{array}{l}1.00 \\
3.53(1.52-8.20)^{\star *}\end{array}$ & $\begin{array}{l}1.00 \\
3.79(1.38-10.37)^{\star}\end{array}$ \\
\hline $\begin{array}{l}\text { Age } \\
60-69 \\
70 \text { and over }\end{array}$ & $\begin{array}{l}1.00 \\
0.66(0.36-1.23)\end{array}$ & $\begin{array}{l}1.00 \\
0.59(0.30-1.16)\end{array}$ & $\begin{array}{l}1.00 \\
0.48(0.22-1.05)\end{array}$ & $\begin{array}{l}1.00 \\
0.41(0.16-1.04)\end{array}$ \\
\hline $\begin{array}{l}\text { Population group } \\
\text { African Black } \\
\text { White } \\
\text { Coloured } \\
\text { Indian or Asian }\end{array}$ & $\begin{array}{l}1.00 \\
1.55(0.54-4.44) \\
0.63(0.18-2.15) \\
0.47(0.12-1.93)\end{array}$ & $\begin{array}{l}1.00 \\
1.95(0.75-5.10) \\
0.49(0.17-1.46) \\
0.40(0.06-2.85)\end{array}$ & $\begin{array}{l}1.00 \\
2.10(0.84-5.28)^{\star} \\
0.53(0.20-1.46) \\
0.52(0.13-2.14)\end{array}$ & $\begin{array}{l}1.00 \\
3.01(1.31-6.89)^{\star} \\
0.48(0.20-1.18) \\
0.51(0.08-3.30)\end{array}$ \\
\hline $\begin{array}{l}\text { Marital status } \\
\text { Single } \\
\text { Married } \\
\text { Separated/Divorced } \\
\text { Widow }\end{array}$ & $\begin{array}{l}1.00 \\
2.59(1.33-5.04)^{\star \star} \\
1.39(0.35-5.55) \\
1.12(0.53-2.37)\end{array}$ & $\begin{array}{l}1.00 \\
1.84(0.70-4.88) \\
0.87(0.14-5.46) \\
1.05(0.47-2.34)\end{array}$ & $\begin{array}{l}1.00 \\
1.63(0.74-3.55) \\
1.90(0.46-7.90) \\
0.83(0.33-2.10)\end{array}$ & --- \\
\hline $\begin{array}{l}\text { Educational level } \\
\text { Less than primary } \\
\text { Primary } \\
\text { Secondary }\end{array}$ & $\begin{array}{l}1.00 \\
0.92(0.48-1.79) \\
0.80(0.33-1.98)\end{array}$ & $\begin{array}{l}1.00 \\
1.00(0.49-2.05) \\
1.44(0.41-5.00)\end{array}$ & $\begin{array}{l}1.00 \\
0.77(0.39-1.51) \\
1.06(0.46-2.46)\end{array}$ & $\begin{array}{l}1.00 \\
0.82(0.43-1.57) \\
1.26(0.45-3.49)\end{array}$ \\
\hline $\begin{array}{l}\text { Wealth } \\
\text { Low } \\
\text { Medium } \\
\text { High }\end{array}$ & $\begin{array}{l}1.00 \\
0.66(0.37-1.17) \\
0.75(0.27-2.11)\end{array}$ & $\begin{array}{l}1.00 \\
0.62(0.32-1.18) \\
0.61(0.23-1.18)\end{array}$ & $\begin{array}{l}1.00 \\
0.59(0.32-1.09) \\
0.86(0.33-2.26)\end{array}$ & $\begin{array}{l}1.00 \\
0.54(0.27-1.09) \\
0.70(0.28-1.73)\end{array}$ \\
\hline $\begin{array}{l}\text { Geolocality } \\
\text { Rural } \\
\text { Urban }\end{array}$ & $\begin{array}{l}1.00 \\
1.14(0.57-2.31)\end{array}$ & --- & $\begin{array}{l}1.00 \\
1.32(0.64-2.70)\end{array}$ & --- \\
\hline $\begin{array}{l}\text { Co-morbidity } \\
\text { Hypertension } \\
\text { Diabetes } \\
\text { Depression } \\
\text { Tobacco use } \\
\text { Obesity }\end{array}$ & $\begin{array}{l}0.72(0.30-1.71) \\
0.12(0.03-0.45)^{\star \star} \\
1.11(0.48-2.59) \\
7.27(3.09-17.12)^{\star \star \star} \\
0.12(0.06-0.23)^{\star \star \star}\end{array}$ & $\begin{array}{l}-- \\
0.28(0.06-1.27) \\
-- \\
6.35(2.47-16.33)^{\star \star \star} \\
0.13(0.05-0.32)^{\star \star \star}\end{array}$ & $\begin{array}{l}0.92(0.41-2.08) \\
0.40(0.13-1.24) \\
0.88(0.29-2.66) \\
5.26(2.31-11.96)^{\star \star \star} \\
0.12(0.06-0.27)^{\star \star \star}\end{array}$ & $\begin{array}{l}\cdots \\
\cdots \\
\cdots \\
5.25(2.20-12.52)^{\star \star \star} \\
0.14(0.05-0.35)^{\star \star \star}\end{array}$ \\
\hline Subjective health status & $1.0390 .49-2.14)$ & & $0.94(0.44-2.01)$ & \\
\hline Activity limitation & $0.96(0.62-1.50)$ & & $0.90(0.59-1.39)$ & \\
\hline $\begin{array}{l}\text { Physical activity } \\
\text { High } \\
\text { Moderate } \\
\text { Low }\end{array}$ & $\begin{array}{l}1.00 \\
0.67(0.30-1.47) \\
0.65(0.31-1.38)\end{array}$ & & $\begin{array}{l}1.00 \\
0.48(0.19-1.25) \\
0.59(0.26-1.36)\end{array}$ & \\
\hline
\end{tabular}

Both heavy and binge drinking were adjusted mutually by gender, age, educational level, wealth and depression 
The study further found that regarding sociodemographics, only male gender and white population group were associated with risky drinking in multivariate analysis; while among co-morbidities, tobacco use and not being obese were associated with risky drinking. Hypertension, diabetes and depression were not associated. In agreement with other studies this study found significantly higher problem drinking among men than women. ${ }^{8,10,14,17}$ This gender difference may be in some way attributed to socio-cultural norms that hinder women to engage in alcohol drinking. The study found that there was a decrease of alcohol use with age but this was not significant, as found in some other studies. 8,14 This would indicate that daily drinking would pose an increasing problem as with ageing and would require specific attention. Further, unlike in other studies ${ }^{15,16}$, depression symptoms and psychological distress were in this study not related with risky drinking. In concordance with other studies $^{25-27}$, this study found an association between tobacco use and hazardous or harmful drinking. Public health interventions should address multiple substance use risk behaviour. The finding that obesity was protective of risky drinking in both older women and men is less clear. Other studies show different relationships between obesity and risky drinking. For example, drinking alcohol increased the odds of being overweight or obese in Chinese older adults ${ }^{28}$ : lower and higher levels of alcohol $\mathrm{use}^{29}$ and women who were heavy drinkers, were less likely to be obese than women who were non-drinkers. ${ }^{30}$

\section{Limitations of the study}

This study had several limitations. Firstly, the self-report of alcohol use should be interpreted with caution; it is possible that respondents underreported alcohol use, especially females. A number of risk factors associated with alcohol misuse or abuse in older adults reported in other studies (such as medication intake which may interact negatively with alcohol and religious involvement ${ }^{3,4,8,13,14,17}$ ), were not assessed and should be assessed in future studies. For co-morbidities, given the limitations of self-reported morbidity, symptom questions and a related diagnostic algorithm were used to ascertain possible presence of co-morbidity conditions.

Furthermore, this study was based on data collected in a cross-sectional survey. We cannot, therefore, ascribe causality to any of the associated factors in the study. Prospective studies are required to follow up alcohol use and associated factors.

\section{Conclusion}

This study reveals moderate rates of risky drinking among older adults (60 years and older) in South Africa that puts them at risk of morbidity. Alcohol problems among older adults are commonly under-recognized, suggesting a need for health care worker intervention. Evidence is needed as the capacity of some African health systems to respond to multiple co-morbidities is limited.

\section{Acknowledgments}

Funding was provided predominantly from the National Department of Health with additional funding provided by
United States National Institute on Aging, WHO and the Human Sciences Research Council. Technical assistance was provided by the WHO, Geneva.

\section{References}

1. Sorocco KH, Ferrell SW. Alcohol use among older adults. Journal of General Psychology 2006; 133(4):453-67.

2. Cummings SM, Bride B, Cassie KM and Rawlins-Shaw A. Substance abuse. Journal of Gerontologial Social Work 50 (Suppl)2008; 21: 541.

3. Stevenson JS. Alcohol use, misuse, abuse, and dependence in later adulthood. Annual Review of Nursing Research 2005; 23:245-80.

4. Moore A, Giuli L, Gould R, et al. Alcohol use, comorbidity, and mortality. J Am Geriatr Soc. 2006; 54(5):757-62.

5. Rehm J, Mathers C, Popova S, Thavorncharoensap $M$, Teerawattananon Y, Patra J. Global burden of disease and injury and economic cost attributable to alcohol use and alcohol-use disorders. Lancet 2009; 373(9682):2223-33.

6. Moore AA, Whiteman EJ, Ward KT. Risks of combined alcohol/medication use in older adults. American Journal of Geriatric Pharmacotherapy 2007; 5(1):64-74.

7. Hirayama F, Lee AH, Binns CW, Okumura C, Yamamoto S. Alcohol consumption by older adults in Central and Southern Japan. Asia Pacific Journal of Public Health 2009; 1 1 (2):170-6.

8. Merrick EL, Horgan CM, Hodgkin D, et al. Unhealthy drinking patterns in older adults: prevalence and associated characteristics. Journal of the American Geriatrics Society 2008; 56(2):214-23.

9. Schultz SK, Arndt S, Lutz GM, Petersen A, Turvey CL. Alcohol use among older persons in a rural state. American Journal of Geriatric Psychiatry 2002; 10(6):750-3.

10. Castro-Costa E, Ferri CP, Lima-Costa MF, Zaleski M, Pinsky I, Caetano R, Laranjeira R. Alcohol consumption in late-life - the first Brazilian National Alcohol Survey (BNAS). Addictive Behavior 2008; 33(12):1598-601.

11. Negin J, Cumming R, de Ramirez SS, Abimbola S, Sachs SE. Risk factors for non-communicable diseases among older adults in rural Africa. Tropical Medicine and International Health 2011 ; 16(5):6406.

12. Aekplakorn W, Hogan MC, Tiptaradol S, Wibulpolprasert S, Punyaratabandhu P, Lim SS. Tobacco and hazardous or harmful alcohol use in Thailand: Joint prevalence and associations with socioeconomic factors. Addictive Behavior 2008;33:503-514.

13. Krause $N$. Race, religion, and abstinence from alcohol in late life. Journal of Aging and Health 2003; 15(3):508-533.

14. Barnes AJ, Moore AA, Xu H, Ang A, Tallen L, Mirkin M and Ettner SL. Prevalence and correlates of at-risk drinking among older adults: The project SHARE study. Journal of General and Internal Medicine 2010; 25(8):840-6.

15. Choi NG, DiNitto DM. Heavy/binge drinking and depressive symptoms in older adults: gender differences. International Journal of Geriatric Psychiatry 201 1; 26(8):860-8.

16. Choi NG, DiNitto DM. Psychological distress, binge/heavy drinking, and gender differences among older adults. American Journal of Addictions 201 1; 20(5):420-8.

17. Towers A, Stephens C, Dulin P, Kostick M, Noone J, Alpass F. Estimating older hazardous and binge drinking prevalence using AUDIT-C and AUDIT-3 thresholds specific to older adults. Drug and Alcohol Dependence 2011; 117(2-3):211-8.

18. National Institute on Alcohol Abuse and Alcoholism. Helping patients who drink too much. A Clinician's Guide. 2005 Edition. Available at: 
http://pubs.niaaa.nih.gov/publications/Practitioner/CliniciansGuide 2005/guide.pdf, Accessed December 5, 2011.

19. Moos RH, Brennan PL, Schutte KK, Moos BS. High-risk alcohol consumption and late-life alcohol use problems. American Journal of Public Health 2004;94(11):1985-91

20. Saitz R. Medical and surgical complications of addiction. In: Graham AST, Mayo-Smith M, Ries R, Wilford BB, ed. Principles of Addiction Medicine (3rd ed): Chevy Chase, MD: ASAM. 2003:1027-52.

21. World Health Organisation (WHO). Global Physical Activity Surveillance. (http://www. who.int/chp/steps/GPAQ/en/index.html, accessed 2 December 2010), 2009.

22. Kessler RC, Ustun TB. The World Mental Health (WMH) Survey Initiative Version of the World Health Organization (WHO) Composite International Diagnostic Interview (CIDI). International Journal of Methods in Psychiatric Research 2004; 13: 93-121.

23. WHO. The ICD-10 classification of mental and behavioural disorders: diagnostic criteria for research (DCR-10). Geneva: World Health Organization, 1993

24. Ayuso-Mateos JL, Nuevo R, Verdes E, Naidoo N, Chatterji S. From depressive symptoms to depressive disorders: the relevance of thresholds. British Journal of Psychiatry 2010; 196(5): 365-71.
25. Dani JA, Harris RA. Nicotine addiction and comorbidity with alcohol abuse and mental illness. Nature Neuroscience 2005; 8(11):146570.

26. Graham NA, Frost-Pineda K, Gold MS. Tobacco and psychiatric dual disorders. Journal of Addictive Disorders 2007; 1:5-12.

27. Blay SL, Fillenbaum GG, Andreoli SB, Gastal FL. Correlates of lifetime alcohol misuse among older community residents in Brazil. International Psychogeriatrics 2009; 21 (2):384-91.

28. Ahn S, Zhao H, Tai-Seale M, Huber C Jr, Smith ML, Ory MG, Phillips $C D$. The longitudinal effects of behavioral, health, and sociodemographic factors on body mass index among older Chinese adults. International Journal of Public Health 2011;Apr 8.

29. Kaplan MS, Huguet N, Newsom JT, McFarland BH, Lindsay J. (2003) Prevalence and correlates of overweight and obesity among older adults: findings from the Canadian National Population Health Survey. The Journals of Gerontology Series A: Biological Sciences and Medical Sciences 2003; 58(11):1018-30

30. Kruger J, Ham SA, Prohaska TR. Behavioral risk factors associated with overweight and obesity among older adults: the 2005 National Health Interview Survey. Preventing Chronic Disease 2009; 6(1):A14

\section{INSTRUCTIONS FOR AUTHORS African Journal of Psychiatry (AJP)}

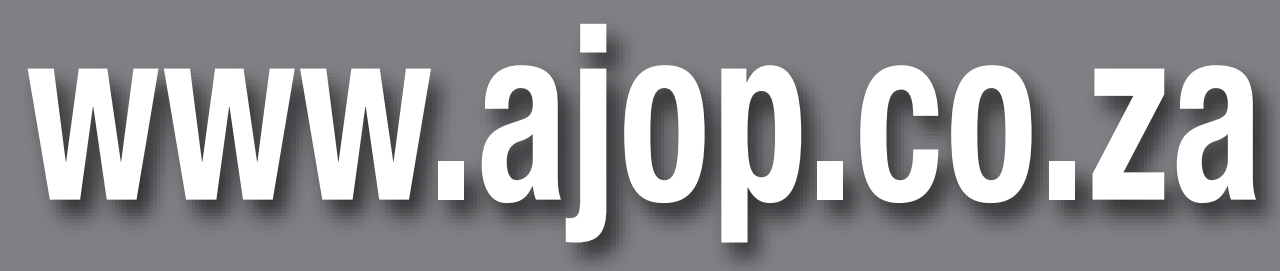

All manuscripts and correspondence should be emailed to:

Professor CP Szabo, email: christopher.szabo@wits.ac.za

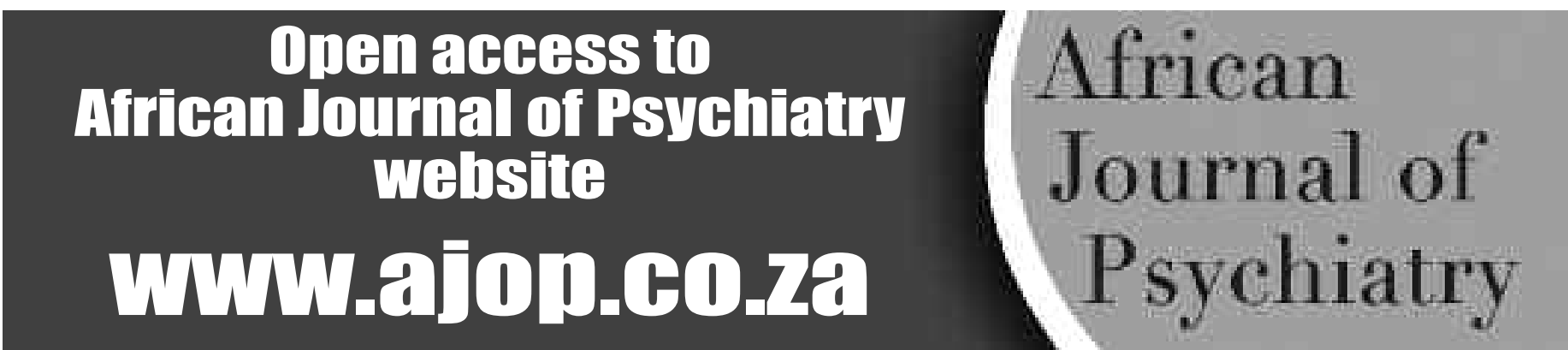

